\title{
PENGEMBANGAN KOMPETENSI MAHASISWA MELALUI PELATIHAN MAGANG ONLINE SAAT PANDEMI COVID 19
}

\author{
Lucky Radi Rinandiyana1, Noneng Masitoh², Andri Helmi Munawar, \\ Tine Badriatin ${ }^{4}$, Rini Muflihah ${ }^{5}$, Sri Sudiarti ${ }^{6}$, Dede Aji Mardani ${ }^{7}$, \\ Fuzi Waliyul Mujtahidin ${ }^{8}$
}

Fakultas Ekonomi dan Bisnis Universitas Siliwangi 1,2,3,4, Sekolah Tinggi Agama Islam Tasikmalaya ${ }^{5,7}$, Politeknik Triguna Tasikmalaya ${ }^{6}$, Politeknik Bisnis Mayasari ${ }^{8}$ ${ }^{*}$ Corresponding Author : tinebadriatin@gmail.com

\begin{abstract}
This activity is carried out in collaboration with 3 Universities in the City of Tasikmalaya with the Financial Services Institution in the Capital Market to develop student competencies through an apprenticeship training program. This activity is carried out for 30 working days starting from February 2021 to March 2021 with a rotating system considering the training period during the Covid 19 pandemic. Internships are carried out online and once a week carried out offline with a rotating system to avoid crowds and maintain health protocols. With this work apprenticeship, it is hoped that students participating in the apprenticeship who are final year students can prepare themselves in the real world of work after graduating from college, where apprenticeships are also expected to be able to apply the theories obtained during college to be able to apply them in companies or institutions where they work. This activity is carried out with assistance from lecturers and tutors from the company. The implementation of this internship resulted in participants being able to learn firsthand the stock trading system at the Indonesia Stock Exchange with direct supervision of the trading market and be able to see how the marketing administration of opening a share account.
\end{abstract}

Keywords: Online Apprenticeship, Capital Market

\begin{abstract}
Abstrak
Kegiatan ini dilaksanakan melalui kerjasama 3 Perguruan Tinggi di Kota Tasikmalaya dengan Lembaga Jasa Keuangan bidang Pasar Modal guna mengembangkan kompetensi mahasiswa melalui program pelatihan magang kerja. Kegiatan ini dilaksanakan selama 30 hari kerja dimulai dari bulan Februari 2021 sampai Maret 2021 dengan sistem bergilir mengingat masa pelatihan dalam masa pandemi covid 19. Magang kerja sendiri dilaksanakan secara online dan seminggu sekali dilaksanakan offline dengan sistem bergilir untuk menghindari kerumunan dan menjaga protokol kesehatan. Dengan magang kerja ini diharapkan mahasiswa peserta magang yang merupakan mahasiswa tingkat akhir dapat mempersiapkan diri di dunia kerja yang nyata setelah lulus kuliah, dimana dengan magang kerja juga diharapkan dapat mengaplikasikan teori yang didapat selama kuliah untuk dapat diimplementasikan di Perusahaan atau instansi tempat bekerja. Kegiatan ini dilakukan dengan pendampingan dari dosen dan tutor dari perusahaan. Adapun pelaksanaan magang ini menghasilkan peserta dapat mempelajari secara langsung sistem perdagangan saham pada Bursa Efek Indonesia dengan mengamati live trade bursa dan dapat mengetahui cara pengadministrasian pemasaran pembukaan rekening saham.
\end{abstract}

Kata Kunci : Magang Online, Pasar Modal 


\section{PENDAHULUAN}

Perguruan tinggi sebagai salah satu wadah pencetak generasi muda yang berpendidikan dimana harus mampu mempersiapkan lulusan mahasiswa yang siap pakai dan siap guna bagi diri dan masyarakat nantinya. Parameter pencapaian keberhasilannya sebagai anggota masyarakat adalah memiliki kemampuan akademis dan profesional yang dapat menerapkan ilmu yang telah dipelajari selama mengikuti perkuliahan. Salah satunya adalah siap dalam menghadapi tantangan global dan persaingan dalam Dunia Usaha / Dunia Industri.

\section{Lulusan Perguruan tinggi} profesional harus dilengkapi dengan keterampilan profesional. Salah satunya adalah penyediaan lulusan untuk mahasiswa profesional yang mempunyai bidang keahlian yang siap pakai untuk dapat diaplikasikan di dunia nyata atau di lingkungan masyarakat nantinya. Untuk menunjang persiapan dunia kerja maka perguruan tinggi juga memfasilitasi untuk dapat mempraktekan keahliannya melalui magang kerja pada berbagai macam Dunia usaha/industri (Du/Di).
Keterlibatan industri dalam penyelenggaraan magang kerja akan memberikan keuntungan bagi industri itu sendiri. Selain sebagai tanggung jawab sosial sesuai undang-undang, bahwa pendidikan menjadi tanggung jawab bersama antara orang tua, sekolah (pemerintah) dan masyarakat, industri dituntut untuk membuka diri membantu sekolah-sekolah vokasi menyiapan lulusannya agar dapat terserap secara cepat oleh DU/DI. Negara-negara Eropa biasanya menjadi contoh yang baik keterlibatan industri dalam pendidikan vokasi (Samidjo, 2017). Untuk meningkatkan pengetahuan agar kita bisa mendapatkan nilai tambah sebelum terjun ke dunia kerja, dimana melalui program ini diharapkan didapat dari pengalaman juga bdapat mempersiapkan untuk nanti setelah lulus, di mana pengembangan dunia pekerja lebih kompetitif dan kebutuhan akan sumber daya manusia dimana kehandalan meminta kita untuk menguasai pengetahuan dalam menjadi karyawan yang diperlukan. Untuk memenuhi tuntutan tersebut maka perguruan tinggi menyelenggarakan 
pelatihan magang sebagai tugas akhir untuk dapat mengembangkan potensi mahasiswanya.

$$
\text { Program ini diharapkan }
$$

mampu menawarkan peluang mahasiswa untuk berlatih terutama dalam bidang kerja di Lembaga Keuangan, khususnya Pasar modal yang telah dipelajari selama periode magang tugas akhir. Selain itu dengan program magang, Pelatihan ini dapat menjalin hubungan kolaborasi bilateral dengan perusahaan di perusahaan magang. Mahasiswa juga dapat berperan dalam memberikan konstribusinya pada perusahaan magang (Sudaryanti, Masitoh, \& Badriatin, 2020). Kegiatan ini bertujuan untuk memperoleh gambaran yang menyeluruh tentang proses pelaksanaan Praktek Kerja Lapangan dimana dapat memberikan kesempatan untuk melihat secara langsung masalahmasalah yang dihadapi pada pelaksanaan Praktek Kerja Lapangan yang diterapkan pada kompetensi keahlian (Atmawati, Samsudi, \& Sudana, 2017).

\section{METODE PELAKSANAAN}

Kegiatan ini dilaksanakan dengan metode Praktek Kerja Lapangan baik secara Offline dan Online. Praktek lapangan merupakan bentuk penyelenggaraan pendidikan dan pelatihan kejuruan yang diikuti oleh siswa dengan bekerja secara langsung di dunia usaha atau dunia industri (DU/DI), secara sistematik dan terarah dengan supervisi yang kompeten di bidangnya dengan tujuan memperoleh pengalaman dan kecakapan penguasaan keahlian di suatu bidang hingga mencapai suatu tingkat keahlian profesional tertentu (Riadi, 2021).

Selain itu Hambalik berpendapat bahwa, praktik kerja lapangan bertujuan untuk mempersiapkan dan membina tenaga kerja, baik struktural maupun fungsional, yang memiliki kemampuan melaksanakan loyalitas, kempuan melaksanakan dedikasi dan kemampuan berdisiplin yang baik (Hambalik, 2011).

Cara yang dilakukan dalam praktek kerja lapangan ini diantaranya menyiapkan lulusan mahasiswa yang unggul dan berkualitas agar siap dalam 
menghadapi tuntutan global (Badriatin,

Rinandiyana, \& Sudiarti, 2020)

Peserta magang dari beberapa perguruan tinggi ini ditempatkan pada Kantor PT. Reliance Sekuritas Indonesia, Tbk Kantor Perwakilan Tasikmalaya dengan pembagian jadwal secara bergilir mulai tanggal 1 Februari 2021 sampai 30 Maret 2021 masing-masing selama 30 hari kerja. Para peserta ini menempati bagian pemasaran bidang edukasi dan literasi pasar modal diamana pemagang selain membantu bagian pemasaran juga membantu bagian administrasi khususnya dalam pencatatan opening account untuk para nasabah baru.

\section{HASIL DAN PEMBAHASAN}

Pelaksanaan praktek kerja lapangan oleh pemagang dari beberapa perguruan tinggi ini dilakukan dengan bekerja sama dengan perusahaan Industri Jasa Keuangan yang ada di Kota Tasikmalaya salah satunya adalah dengan PT. Reliance Sekuritas Indonesia, Tbk Kantor Perwakilan Tasikmalaya yaitu Industri Jasa Keuangan yang bergerak di bidang Pasar Modal.
Pemagang ditempatkan di bagian Pemasaran khususnya bidang Edukasi, Literasi dan Inklusi Pasar Modal serta membantu salah satu proses pengadministrasian data oleh bagian Staf Admin. Bagian ini diperlukan dimana untuk membantu pemahaman terlebih dahulu kepada masyarakat tentang pasar modal karena bagaimanapun juga pasar modal tidak akan diketahui oleh masyarakat tanpa adanya dukungan pengetahuan tentang berinvestasi di pasar modal (IDX, 2017).

Adapun sistem pelaksanaannya adalah melalui offline dan online dimana cara ini dilakukan untuk mengantisipasi dan melaksanakan protokol kesehatan dalam masa pandemi covid 19. Pelaksanaan offline dilakukan melalui pertemuan tatap muka 1x dalam 1 minggu secara bergilir agar menghindari bentuk kerumunan. Sedangkan pelaksanaan kegiatan online dilakukan melalui aplikasi zoom meeting dengan pemberian pelatihan edukasi dan literasi pasar modal serta hasil akhirnya adalah pelaksanaan webinar pasar modal secara daring/online.

Lucky Radi Rinandiyana, dkk., Pengembangan Kompetensi Mahasiswa Melalui Pelatihan Magang Online Saat Pandemi Covid 19 
Praktek kegiatan yang materi magang seperti dapat dilihat dilakukan secara offline dan online ini dalam tabel berikut ini : diantaranya melalui penyampaian

Table 1. Materi Magang Online

\begin{tabular}{cl}
\hline No. & \multicolumn{1}{c}{ Materi Magang Online } \\
\hline 1. & Pengenalan Pasar Modal di Indonesia \\
2. & Materi Dasar tentang saham dan equity lainnya \\
3. & Pengetahuan dasar mengenai sertifikasi license pasar \\
& modal \\
4. & Profil Manajemen Reliance Group \\
5. & Presentasi Edukasi Pemasaran Pasar Modal \\
6. & Pengenalan Aplikasi Relitrade Next-G Lite \\
7. & Capital Market Career \\
8. & Tips dan tahapan berkarir di dunia pasar modal \\
\hline
\end{tabular}

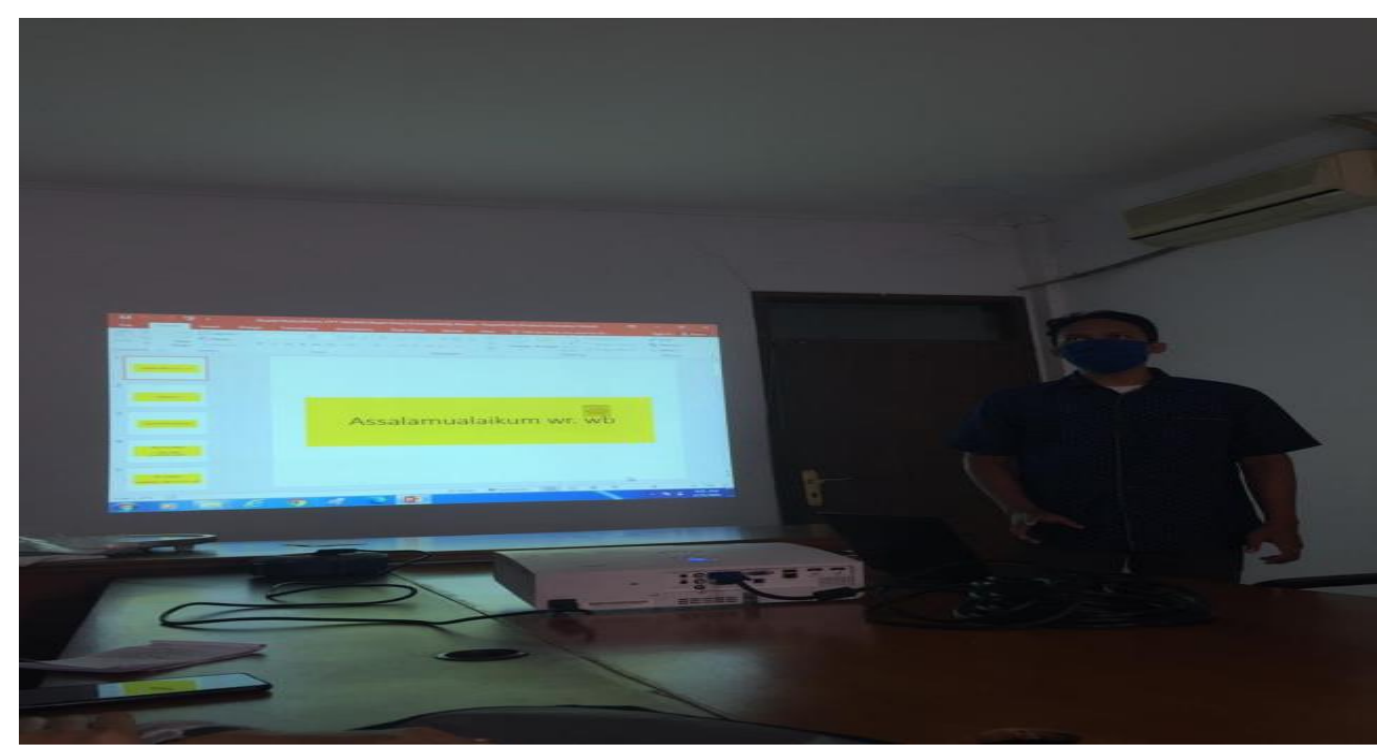

Gambar 1. Latihan Menyampaikan Sosialisasi Pasar Modal sebagai bagian dari Staf Pemasaran bagian edukasi melalui Aplikasi Zoom Meeting 


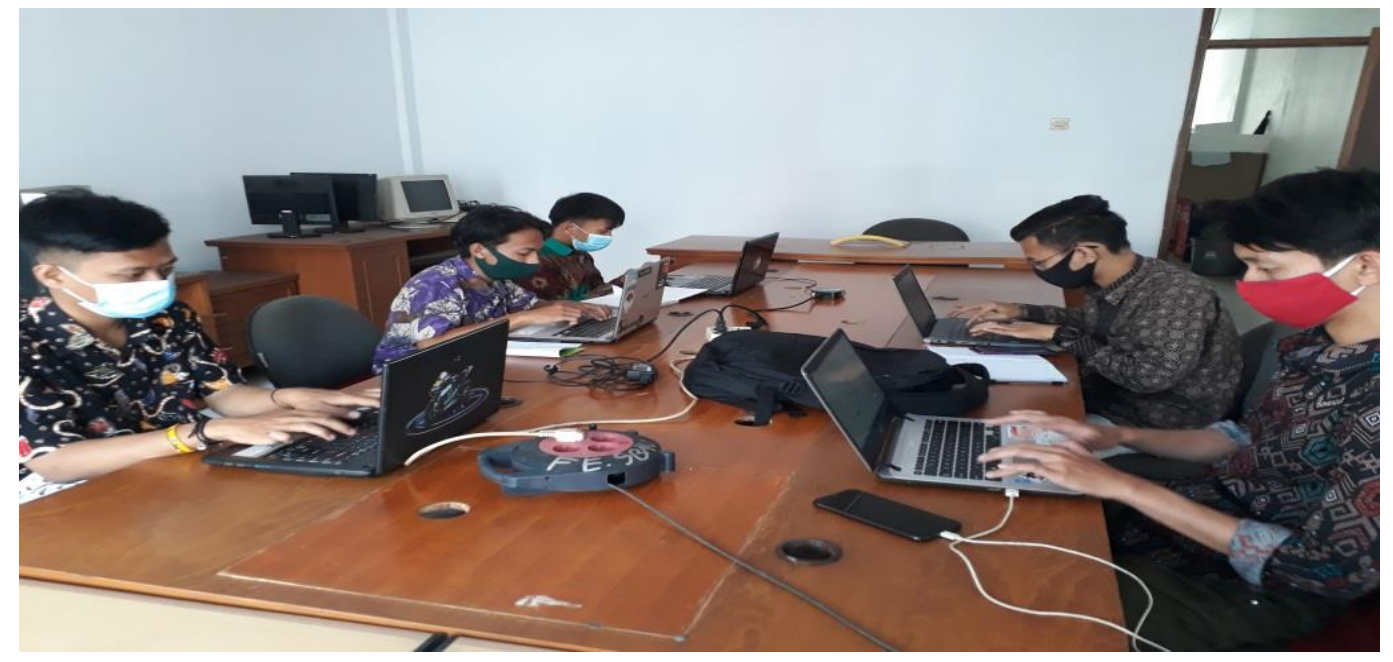

Gambar 2. Pemagang dari Universitas Siliwangi dalam kegiatan praktek kerja lapangan secara offline

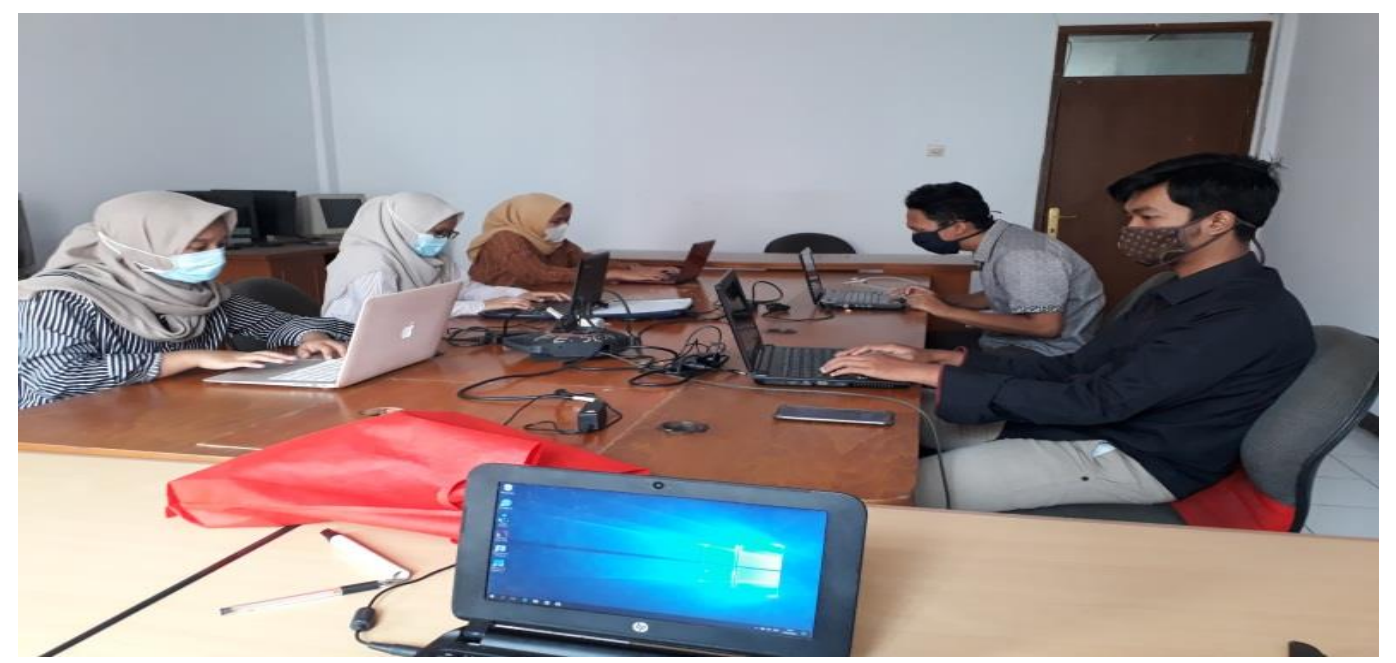

Gambar 3. Pemagang dari STAI dalam kegiatan magang offline

Materi online yang

disampaikan dilakukan oleh pemateri dari Perusahaan selain dengan pendampingan dari Dosen Pembimbing pemagang. Untuk kegiatan offline dari pemagang yaitu membantu staf administrasi dalam pelaksanaan input data dan pengisian serta pengajaran tata cara opening account untuk para nasabah baru serta tata cara pengisian pengkinian data nasabah untuk nasabah existing. Namun demikian pengisian dan tata cara opening account ini hanyalah bentuk pembelajaran tidak diperkenankan pengisian dalam aplikasi yang asli atau yang sebenarnya karena untuk menghindari kerahasiaan data nasabah. 


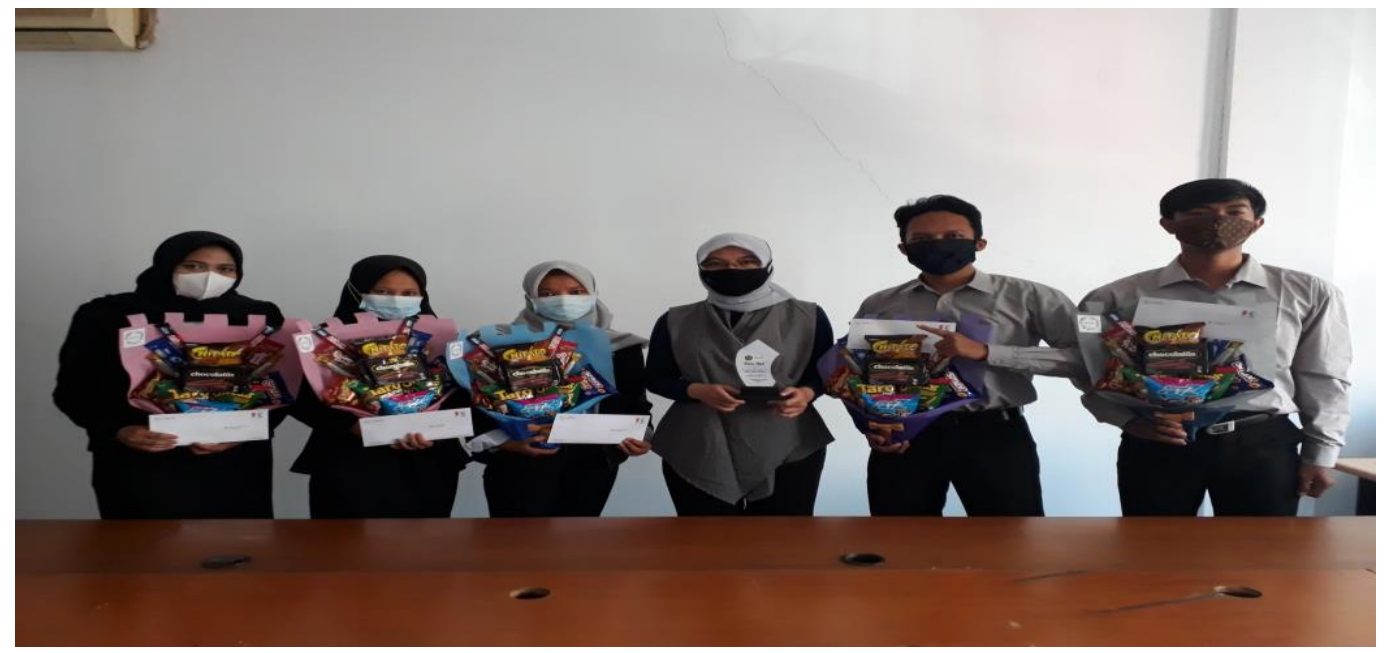

Gambar 4. Penyerahan Plakat dari Pemagang UNSIL kepada Pimpinan Perusahaan

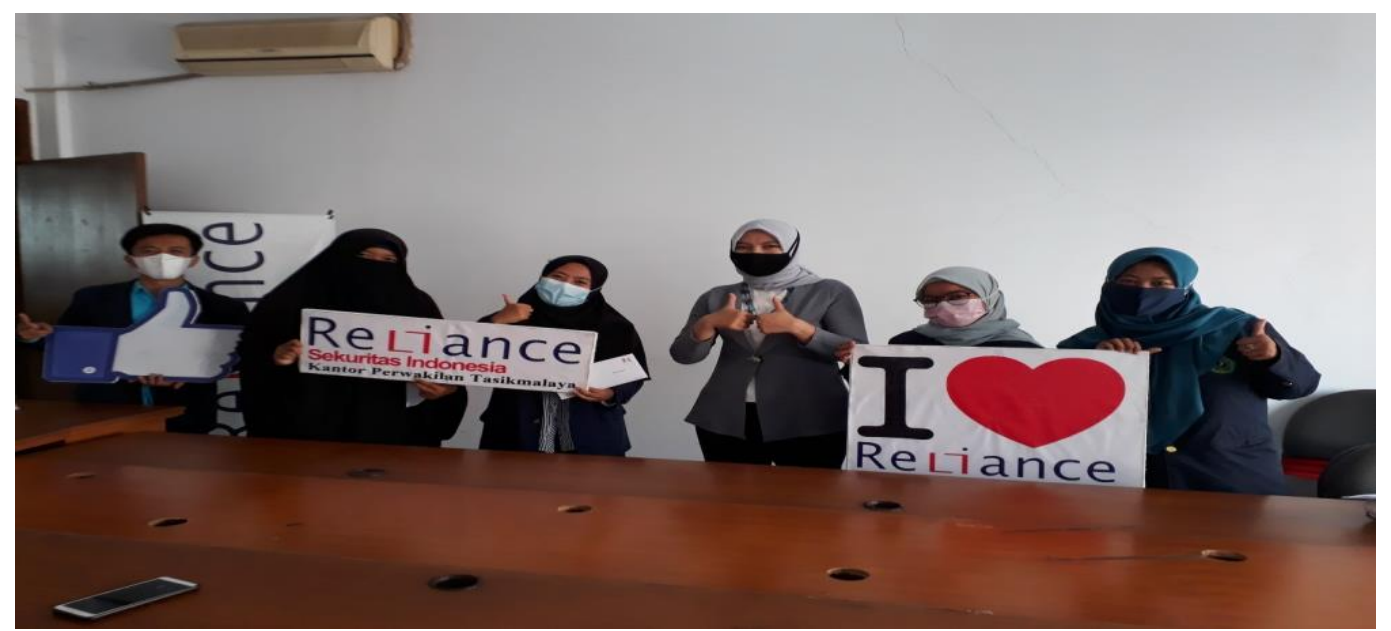

Gambar 5. Pelepasan / perpisahan peserta magang oleh Pimpinan Perusahaan dengan perwakilan pemagang dari STAI Tasikmalaya

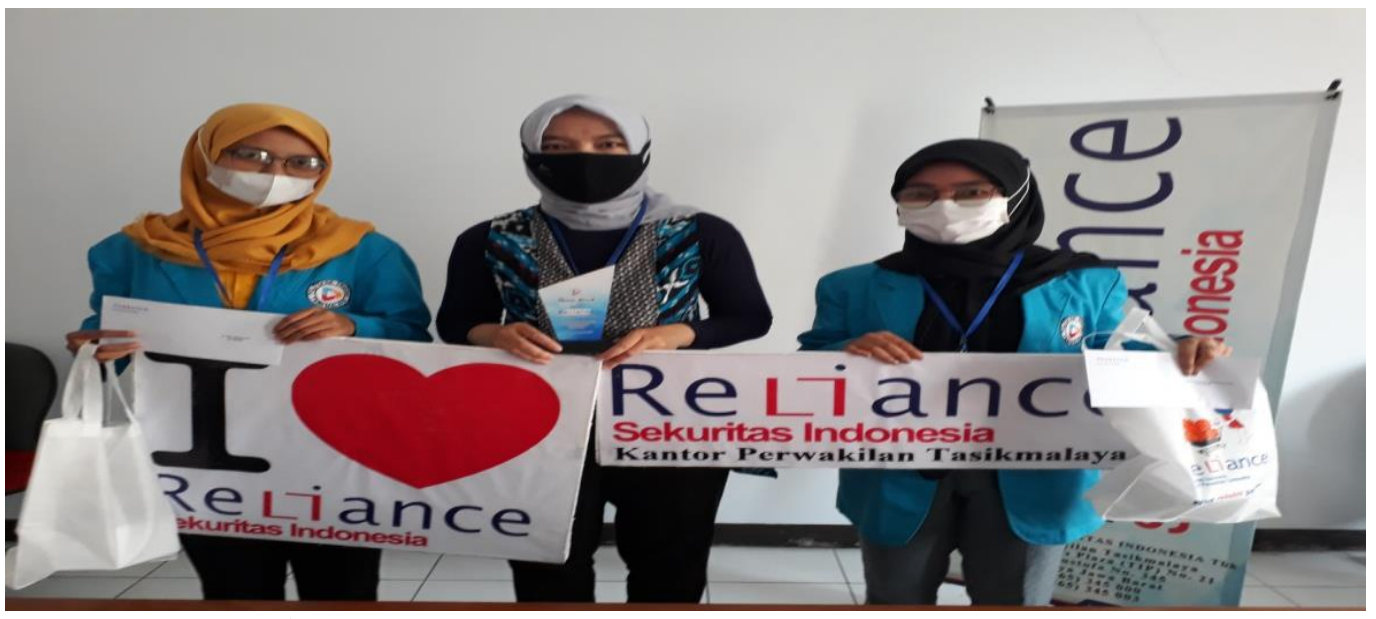

Gambar 6. Penyerahan Plakat dan Merchandise kepada

Pimpinan Perusahaan oleh Pemagang Politeknik Triguna 


\section{SIMPULAN}

Kerjasama dengan Dunia Usaha/ Dunia Industri (Du/Di) dalam kegiatan ini merupakan salah satu bentuk kegiatan pengabdian kepada masyarakat terutama ditujukan kepada mahasiswa tingkat akhir untuk dapat pembekalan dimana disiapkan dalam menghadapi karier nyata di masyarakat agar siap dalam memberikan kontribusi ilmu yang telah didapat semasa kuliah di perguruan tinggi. Kegiatan Praktek Kerja Lapangan melalui magang offline dan online pada perusahaan ini telah efektif dapat membantu pemagang hal ini dapat dilihat diantaranya dalam presentasi akhir pemagang sudah dapat memaparkan produk perusahaan dimana dalam penempatan pemagang sebagai bagian pemasaran bidang edukasi telah dapat dipahami dan diaplikasikan.

Kegiatan lain yang dihasilkan dalam kegiatan ini adalah pemagang sudah dapat mengetahui cara kerja sistem perdagangan di Bursa Efek Indonesia secara langsung dengan melihat dalam aplikasi Relitrade, pemagang juga sudah mahir dalam membantu proses pengadministrasian rekening dimana telah dicatat dan diarsipkan dengan baik.

Namun demikian keterbatasan pelaksanaan kegiatan ini dimana kegiatan offline nya harus dibatasi melalui online dan bekerja dari rumah (Work From Home/WFH) membuat praktek kerja ini kurang maksimal, tetapi hal ini tidak menjadikan pemagang tidak dapat mengaplikasikan praktek kerja lapangan hanya saja waktunya yang terbatas. Untuk itu diperlukan pembelajaran lebih lanjut untuk dapat mempraktekan dunia kerja di Industri Keuangan khususnya Pasar Modal

\section{UCAPAN TERIMAKASIH}

Penulis ucapkan terima kasih yang tak terhingga kepada PT. Reliance Sekuritas Indonesia, Tbk Kantor Perwakilan Tasikmalaya yang telah memberikan bantuan dan kerjasamanya serta bimbingannya dalam kegiatan ini. 


\section{REFERENSI}

Atmawati, Samsudi, \& Sudana, I. M. (2017). Keefektifan Pelaksanaan Praktek Kerja Lapangan Berbasis Industri pada. Journal of Vocational and Career Education, Vol. 2, No. 2, $1-8$.

Badriatin, T., Rinandiyana, L. R., \& Sudiarti, S. (2020). PELATIHAN

INVESTASI SEJAK DINI MELALUI PASAR MODAL PADA MAHASISWA BARU POLITEKNIK TRIGUNA TASIKMALAYA. JCES (Journal of Character Education Society), 8-16, Vol. 3, No. 1.

Hambalik, O. (2011). Proses Belajar Mengajar. Jakarta: PT Bumi Aksara.

IDX. (2017). Belajar Pasar Modal. retrieved from : www.idx.co.id.

Riadi, M. (2021). Praktik Kerja Lapangan (Pengertian, Tujuan, Manfaat, Pelaksanaan dan Penilaian). retrieved from https://www.kajianpustaka.com/2021 103/praktik-kerja-lapangan.html.

Samidjo. (2017). Efektifitas Pelaksanaan Magang Industri Mahasiswa Program Studi Pendidikan Teknik
Mesin. Jurnal Taman Vokasi, Vol. 5, No.2, Desember 2017.

Sudaryanti, D. S., Masitoh, N., \& Badriatin, T. (2020). Pendampingan Praktek Magang Pada Industri Jasa Keuangan oleh Mahasiswa Program Studi Keuangan dan Perbankan Universitas Siliwangi Tasikmalaya. Bantenese Jurnal Pengabdian Masyarakat, Vol. 2, No.1, 34-41. 